\title{
HUBUNGAN SELF EFFICACY TERHADAP PERILAKU KECEMASAN KELAS X SMK NEGERI 2 KARANG BARU ACEH TAMIANG TAHUN PELAJARAN 2019/2020
}

\author{
${ }^{1}$ Nurkholisah , ${ }^{2}$ Nurul Hasanah \\ ${ }^{1}$ Mahasiswa STKIP Budidaya Binjai Prodi Bimbingan dan Konseling, ${ }^{2}$ Dosen STKIP Budidaya
}

\begin{abstract}
ABSTRAK
Permasalahan yang dibahas pada penelitian ini adalah tentang hubungan self efficacy terhadap kecemasan. Tujuan penelitian ini adalah untuk mengetahui hubungan self efficacy terhadap kecemasan siswa kelas $\mathrm{X}$ SMK Negeri 2 Karang Baru Aceh Tamiang Tahun Pelajaran 2019/2020.Dalam penelitian ini dapat didefenisiskan bahwa self efficacy adalah kemampuan untuk membuat keputusan dan penilaian-penilaian tanpa harus bergantung pada orang lain,Sedangkan kecemasan adalah seuatu pengalaman subjekif mengenai ketegangan mental kesukaran dan tekanan yang menyertai konflik atau ancaman.Selain mempengaruhi tingkat aspirasi, situasi belajar yang menekan juga cenderung menimbulkan kecemasan diri siswa. Populasi berjumlah enam puluh siswa, terdiri dari dua kelas yang masing-masing kelas terdapat 30 orang siswa. Berdasarkan pendapat Suharsimi Arikunto, maka sampel yang diambil 60 orang. Instrument yang digunakan adalah dengan menyebarkan angket pada seluruh sampel sebagai bahan masukan untuk mengetahui situasi yang sebenarnya di SMK Negeri 2 Karang Baru Aceh Tamiang,dengan jenis penelitian kuantitatif dan analisis datanya menggunakan korelasi product moment. Dari hasil korelasi yang besarnya 0,978 maka koefesien korelasi ynag ditemukan adalah sangat kuat, sedangkan $r$ tabel adalah 0,312 dan hasil dari $t_{\text {hitung }}>$ $\mathrm{t}_{\text {tabel }}$ yaitu 28,643 >2,02 maka dari itu $\mathrm{Ha}=$ diterima dan Ho $=$ ditolak. Terdapat hubungan self efficacy terhadap kecemasan siswa kelas X Karang Baru Aceh Tamiang Tahun Pelajaran 2019/2020.
\end{abstract}

Kata kunci : kecemasan, Self Efficacy

\section{PENDAHULUAN}

Remaja adalah periode penting dalam rentang kehidupan manusia, karena masa remaja adalah suatu periode peralihan dari masa kanak-kanak ke masa dewasa. Pada masa ini remaja merasakan adanya perubahan yang terjadi pada dirinya seperti perubahan fisik yang hampir menyerupai orang dewasa atau yang biasa disebut dengan masa puber, perubahan sikap, perasaan atau emosi yang sering tanpa disadari oleh remaja itu sendiri seperti rasa malu, gembira, iri hati, sedih, takut, cemas, cemburu, kasih sayang dan rasa ingin tahu (Desiani, 2018).

'Masa remaja adalah masa transisi dari anak-anak menuju dewasa yang meliputi berbagai macam perubahan diantaranya perubahan biologis, kognitif, sosial dan emosional' '(Sihombing, 2017).Kecemasan pada remaja biasanya terjadi dikarenakan banyaknya masalah yang sering dialami oleh remaja antara lain penyalahgunaan obat-obatan, kenakalan remaja, masalah seksual dan masalah yang berhubungan dengan sekolah. Masalah yang berhubungan dengan sekolah misalnya penyesuaian diri, beban pelajaran dan prestasi belajar. Banyaknya permasalahan yang dihadapi membuat cemas dan stress.

Kecemasan adalah hal yang wajar dialami terjadi dalam kehidupan manusia. Apa pun, dimana pun dan kapan pun pasti terjadi dan selalu menyertai hati manusia. Orang tidak mempunyai rasa cemas akan di golongkan abnormal, sebab tidak memiliki atau kehilangan rasa telah dianugrahkan Allah. Namun, apabila kecemasan tidak terkontrol akan membahayakan jiwa dan menghambat kesuksesan. 
Cemas berasal dari bahasa latin anxius dan dalam bahasa jerman angst kemudian axiety yang berati kecemasan, merupakan suatu kata yang digunakan oleh Frued untuk menggambarkan suatu efek negative dan keterangsangan (Delfinasari, 2015). Kecemasan yang dialami remaja biasanya disebabkan oleh beberapa faktor.

Faktor-faktor yang mempengaruhi kecemasan yaitu :

1) faktor yang bersumber dari dalam diri individu ( faktor internal),

2) faktor yang bersumber dari lingkungan (faktor eksternal).

Menurut Kaplan dalam (Hartono, 2012)

'faktor yang bersumber dari individu adalah faktor biologis, kondisi tubuh dan tingkah laku. Faktor biologis yaitu genetik. Faktor kondisi tubuh yaitu penyakit krimis atau cacat tubuh. Faktor tingkah laku, yaitu, gaya hidup yang tidak baik, seperti merokok dan minumminuman berakohol', Menurut Hawari dalam (Hartono, 2012)' faktor lingkungan (eksternal) yang mempengaruhi kecemasan mencakup faktor permasalahan keluarga (keluarga broken home, percerian orang tua, dan permasalahan psikososial keluarga tertentu, kecelakaan, dan kematian keluarga',

Beberapa penelitian mengungkapkan bahwa siswa yang di besarkan di lingkungan sosial keluarga tidak baik akan kepribadian anti-sosial dibandingkan dengan siswa yang di besarkan di lingkungan keluarga harmonis. Agar mengurangi kecemasan pada remaja maka di perlukannya Self efficacy dipercayai memiliki pengaruh terhadap berbagai macam proses kognitif. Semakin tinggi self efficacy seseorang, semakin besar pula harapan yang menantang individu untuk semakin mempersiapkan dirinya dan semakin kokoh pula komitmennya. Kepercayaan siswa terhadap self efficacy membentuk macammacam skenario antisipatorik. Siswa yang memiliki self efficacy tinggi selalu menggambarkan skenario keberhasilan sehingga memicu untuk terus berjuang, sedangkan siswa yang memiliki self efficacy rendah selalu membayangkan kegagalan.

Agar siswa mampu meraih harapannya dibutuhkan self efficacy yang tinggi sehingga siswa mampu mengatasi situasi tertekan, mengubah kegagalan menjadi peluang, dan mengalihkan kemunduran menjadi harapan.Bila siswa memiliki self efficacy rendah, kemampuan berfikir dan analilsisnya terhadap situasi menjadi semakin tidak menentu, aspirasi semakin rendah, dan kualitas hasil pekerjaan semakin buruk (Listiani, 2013). Bandura menyatakan 'bahwa self-efficacy berguna untuk melatih kontrol terhadap stressor yang berperan penting dalam terbangkitnya kecemasan'. Baron dan Byrne mengemukakan 'bahwaself-efficacy merupakan penilaian individu terhadap kemampuan atau kompetensinya untuk melakukan suatu tugas, mencapai suatu tujuan dan menghasilkan keyakinan'. Sedangkan Feist \& feist menyatakan bahwa self-efficacy adalah keyakinan individu bahwa mereka memiliki kemampuan dalam mengadakan kontrol terhadap pekerjaan mereka terhadap peristiwa lingkungan mereka sendiri.",

Remaja yang memiliki self efficacy yang baik biasanya tekun, bermotivasi, berdaya usaha tinggi, tabah dalam mengerjakan suatu kegiatan untuk memperoleh suatu keberhasilan. Suka mencari situasi baru dan bersosialisasi dengan lingkungan sekitar menganggap suatu pekerjaan yang sulit sebagai suatu tantangan yang harus dikuasai bukan sebagai suatu ancaman,memiliki ketertarikan dan keasyikan dalam suatu kegiatan memilih target yang menantang, dan memperhatikan suatu komitmen yang kokoh terhadap tujuan utamanya, mudah membangkitkan kepercayaan diri dan aspirasi yang tinggi sehingga tetap 
bertahan setelah mendapati suatu kegagalan, mengganggap kegagalan diakibatkan kurangnya efisiensi suatu usaha, kurangnya pengetahuan, dan keterampilan yang diperlukan, tenang menghadapi pekerjaan yang sulit.

Selalu menyiapkan diri untuk menghadapi tantangan dan menggunakan analisis pemikiran dengan baik saat menghadapi situasi tertekan, kegagalan dan kemunduran. Bandura menjelaskan, bahwa self efficacy berperan untuk menurunkan kecemasan dalam menghadapi berbagai tantangan dengan tingat kesulitan yang berbeda dikehidupan sehari-hari.

Pendapat tersebut dapat dimaknai bahwa setiap individu yang memiliki self efficacy tinggi akan lebih tekun dalam menyelesaikan berbagai tantangan kehidupan, sedikit merasa cemas, dan tidak mengalami despresi, sedangkan individu yang memiliki keterampilan sosial yang kurang, tanggapan terhadap lingkungan di sertai kecemasan, adanya keinginan menghindari interaksi interpersonal, serta cenderung lebih depresi (Listiani, 2013).

Berdasarkan pengamatan peniliti lakukan masih banyak ditemukan kecemasan yang berlebihan pada siswa, seperti khawatir nilai ujiannya buruk dan masa depan yang buruk. Masih banyak siswa yang memiliki self efficacy yang rendah seperti, mudah menyerah saat menemui tugas yang sulit dan lebih memilih mengandalkan orang lain, gampang merasa stress saat dihadapkan dengan tugas yang sulit. Ketidakmampuan dalam menyesuaikan diri pada lingkungan sekolah biasanya menunjukan sikap seperti, mudah marah, menunjukan kekhawatiran dan kecemasan, sering merasa tertekan (stress atau depresi), bersikap kejam atau senang mengganggu orang lain yang usianya lebih muda, mempunyai kebiasaan berbohong, kurang memiliki rasa tanggung jawab, bersifat pesimis dalam menghadapi kehidupan. Seharus mereka lebih bisa berprilaku optimis dalam menjalani kehidupannya ini agar tercapainya self efficacy yang baik.

Berdasarkan latar belakang yang telah diuraikan diatas maka timbul keinginan untuk melakukan penelitian dengan judul "Hubungan self efficacy terhadap kecemasan kelas X SMK Negeri 2 Karang Baru Aceh Tamiang,"

\section{METODOLOGI PENELITIAN}

Lokasi dari penelitian ini adalah SMK Negeri 2 Karang Baru Aceh Tamiang. Penelitian ini dilaksanakan pada semester ganjil tahun pelajaran 2019/2020. Adapun jenis penelitian ini adalah kuantitatif. Populasi adalah keseluruhan siswa kelas $\mathrm{X}$ SMK KARANG BARU Aceh Tamiang, yang berjumlah 60 orang dari 2 kelas. Teknik pengambilan sampel menggunakan random sampling, yaitu pengambilan sampel dilakukan random pada kelompok-kelompok unit yang kecil atau kluser dan bukan secara individu. Variabel yang digunakan dalam penelitian ini yaitu variabel bebas dan terikat. Variabel bebas dalam penelitian ini adalah self efficacy sebagai tindakan preventif. Variabel terikat adalah variabel yang dipengaruhi atau yang diselidiki hubungannya. Dalam penelitian ini yang dijadikan variabel terikatnya adalah kecemasan. Alat yang digunakan untuk mengumpulkan data primer dalam penelitan ini adalah kuesioner. Teknik yang sering digunakan para peneliti untuk uji validitas adalah menggunakan korelasi. Bervariate Pearson (Product Moment Person) oleh karena itu validasi adalah suatu ukuran yang menunjukan tingkat keabsahan suatu tes. 


\section{HASIL PENELITIAN DAN} PEMBAHASAN

\section{A. Subjek Penelitian}

Deskripsi subjek penelitian dilakukan dengan tujuan agar mengetahui hubungan self efficacy terhadap kecemasan siswa kelas $\mathrm{X}$ SMK Negeri 2 Karang Baru Aceh Tamiang Tahun Pelajaran 2019/2020.

\begin{tabular}{llll}
\hline No & Jenis kelamin & Jumlah & $\mathbf{\%}$ \\
\hline 1. & Perempuan & 12 & $20 \%$ \\
\hline 2. & Laki - Laki & 18 & $80 \%$ \\
\hline & Jumlah & $100 \%$
\end{tabular}

\section{B. Uji Standart Normalitas}

Uji normalitas dilakukan untuk mengetahui apakah distribusi data penelitian setiap variabel telah menyebar secara normal. Uji normalitas dilakukan dengan metode satistik menggunakan program SPSS Version 20.0 .

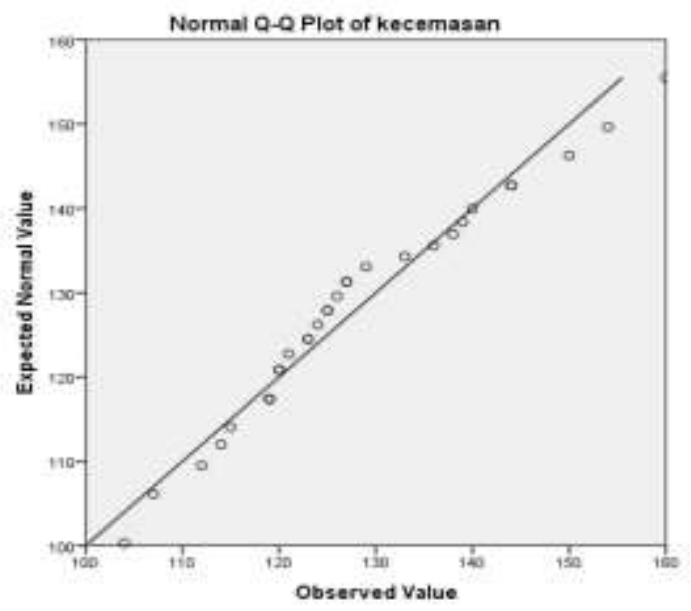

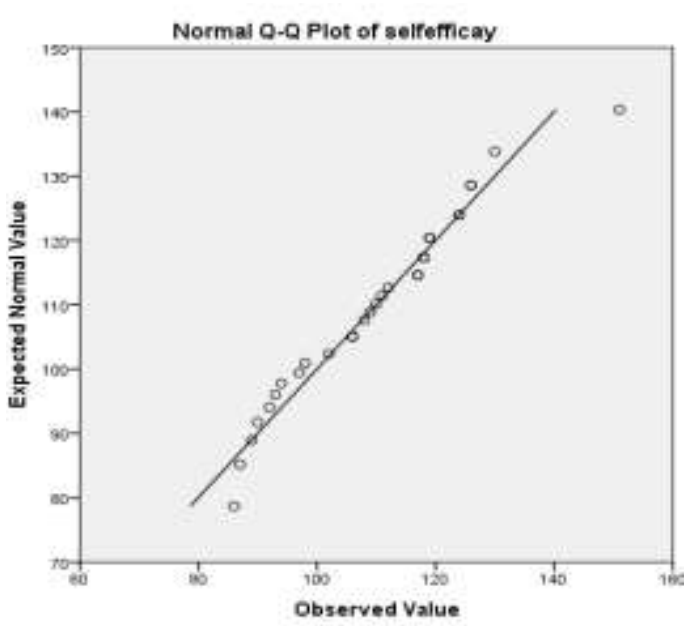

Berdasarkan pada diagram diatas dapat dilihat nilai variabel hubungan self efficacy terdistribusi secara normal terlihat dari item yang terdekat dengan diagram.

\section{Uji Linearitas}

Uji Linearitas bertujuan untuk mengetahui apakah dua variabel mempunyai hubungan yang linear atau tidak secara signifikan. Berikut adalah hasil uji linearitas.

ANOVA Table

\begin{tabular}{|c|c|c|c|c|c|c|c|}
\hline & & & $\begin{array}{l}\text { Sum of } \\
\text { Squares }\end{array}$ & $\mathrm{df}$ & $\begin{array}{l}\text { Mean } \\
\text { Squar } \\
\text { e }\end{array}$ & $\mathrm{F}$ & Sig. \\
\hline \multirow{5}{*}{$\begin{array}{l}\text { selfeffi } \\
\text { cay } * \\
\text { kecema } \\
\text { san }\end{array}$} & \multirow{3}{*}{$\begin{array}{l}\text { Betw } \\
\text { een } \\
\text { Grou } \\
\text { ps }\end{array}$} & $\begin{array}{l}\text { (Com } \\
\text { bined } \\
\text { ) }\end{array}$ & 6211.333 & 22 & $\begin{array}{l}282.3 \\
33\end{array}$ & $\begin{array}{l}4.8 \\
90\end{array}$ & $\begin{array}{l}.01 \\
9\end{array}$ \\
\hline & & $\begin{array}{l}\text { Linea } \\
\text { rity }\end{array}$ & 5.107 & 1 & 5.107 & $\begin{array}{l}.08 \\
8\end{array}$ & $\begin{array}{l}.77 \\
5\end{array}$ \\
\hline & & $\begin{array}{l}\text { Devia } \\
\text { tion } \\
\text { from } \\
\text { Linea } \\
\text { rity }\end{array}$ & 6206.226 & 21 & $\begin{array}{l}295.5 \\
35\end{array}$ & $\begin{array}{l}5.1 \\
19\end{array}$ & $\begin{array}{l}.01 \\
7\end{array}$ \\
\hline & $\begin{array}{l}\text { Within } \\
\text { Groups }\end{array}$ & & 404.167 & 7 & $\begin{array}{l}57.73 \\
8\end{array}$ & & \\
\hline & Total & & 6615.500 & 29 & & & \\
\hline
\end{tabular}

Berdasarkan tabel diatas dapat dilihat bahwa nilai linearitas sebesar 0,775 atau $\mathrm{P}>$ 0,05 yang artinya kedua variabel berhubungan secara signifikan.

\section{Hasil Hipotesis}


Hasil penelitian dilakukan untuk menguji hipotesis penelitian yang mana hipotesis penelitian yang mana hipotesis penelitan adalah :

1) Ho : ada hubungan self efficacy terhadap kecemsan pada siswa kelas $\mathrm{X}$ SMK Negeri 2 Karang Baru Aceh Tamiang.

2) $\mathrm{Ha}$ : tidak ada ada hubungan self efficacy terhadap kecemsan pada siswa kelas X SMK Negeri 2 Karang Baru Aceh Tamiang.

Berikut adalah hasil penelitian hubungan self efficacy terhadap kecemsan pada siswa kelas X SMK Negeri 2 Karang Baru Aceh Tamiang.Hasil penelitian dilakukan menggunakan SPSS Version 20.0.

\section{Correlation}

\begin{tabular}{llll}
\hline & & Kecemasan & Selfefficay \\
\hline kecemasan & $\begin{array}{l}\text { Pearson } \\
\text { Correlation }\end{array}$ & 1 & -.028 \\
& Sig. (2-tailed) & & .884 \\
& $\mathrm{~N}$ & 30 & 30 \\
\hline selfefficay & Pearson & -.028 & 1 \\
& Correlation & & \\
& Sig. (2-tailed) & .884 & 30 \\
& $\mathrm{~N}$ & 30 &
\end{tabular}

Dari tabel diatas dapat diketahui bahwa nilai korelasinya adalah 0,005 yang $\mathrm{P}<0,05$ maka yang artinya Ho diterima bahwa terdapat hubungan self efficacy terhadap kecemasan.

\section{Hasil Penilitian}

Dari hasil penelitian yang didapat subjek yang berjenis perempuan berjumlah 12 orang dan laki - laki 18 orang. Berdasarkan hasil deskripsi diketahui hubungan self efficacy terhadap kecemsan pada siswa kelas X SMK Negeri 2 Karang Baru Aceh Tamiang Tahun Pelajaran 2019/2020 adalah P>0,005 yang mana terdapat penelitian hubungan self efficacy terhadap kecemsan pada siswa kelas X SMK Negeri 2 Karang Baru Aceh Tamiang. Penelitian adalah uraian tentang hal-hal yang berkaitan dengan proses kegiatan penelitian.

Oleh karena itu isi laporan penelitian bukan hanya langkah-langkah yang telah dilakukan oleh peneliti saja. Hasil penelitian dilakukan untuk menguji hipotesis penelitian yang mana hipotesis penelitian adalah:

1) Ho : ada hubungan self efficacy terhadap kecemsan pada siswa kelas $\mathrm{X}$ SMK Negeri 2 Karang Baru Aceh Tamiang.

2) Ha : Tidak ada hubungan self efficacy terhadap kecemsan pada siswa kelas $\mathrm{X}$ SMK Negeri 2 Karang Baru Aceh Tamiang.

\section{Penjelasan secara Teori}

Penelitian ini bertujuan untuk menemukan hubungan self efficacy terhadap kecemasan pada sampel siswa kelas X SMK Negeri 2 Karang Baru Aceh Tamiang tahun Pembelaajran 2019/2020. Hasil pengujian hipotesis menggunakan teknik korelasi product moment menunjukan bahwa nilai signifikan ( $0,884)$ yang berarti lebih besar dari $\alpha(0,05)$. Hal ini berarti bahwa tidak ada hubungan signifikan antara self efficacy terhadap kecemasan output SPSS Juga menunjukan nilai koefisien korelasi antara self efficacy terhadap kecemasan dalam penelitian inin mencapai $r=$ - 0,28. Hal ini berarti bahwa korelasi kedua variabel memiliki arah korelasi yang negative. Korelasi negative berarti apabila variabel self efficacy rendah maka, individu cenderung memiliki kecemasan yang tinggi. Sebaliknya, apabila variabel self efficacy tinggi maka, Individu cenderung memilki kecemasan yang rendah. Hal ini berbeda pada penelitian yang dilakukan oleh Hassal et.al dengan judul communication apprehension and 
communication self efficacy in accounting student yang menyatakan bahwa ada hubungan antara kedua variabel. Penelitian tersebut menjelaskan bahwa sumber self efficacy yang paling berpengaruh untuk menurunkan cominication apprehension adalah enactive mastery experience.

Namun hal ini berbeda dengan Hasil penelitian serupa dengan hasil penelitian McDougall dan Kang (2003) menyatakan adanya korelasi negative antara self efficacy dengan kecemasan ( dalam bulletin psikologi, 2012 ). Penelitian tersebut menjelaskan bahwa sumber self efficacy yang paling berpengaruh untuk menurunkan kecemasan. Tidak adanya hubungan antara self efficacy terhadap kecemasan pada siswa kelas X SMK Negeri 2 Karang Baru Aceh Tamiang mungkin dikarenakan ada faktor yang mempengaruhi kecemasan pada siswa. Self efficacy yang dimiliki oleh subjek perempuan dalam penelitian ini yaitu 4 subjek ketegori rendah, 25 subjek dalam ketegori sedang dan 11 subjek dengan kategori tinggi. Hal ini berarti bahwa siswa SMK Negeri 2 Karang Baru kelas X hanya sedikit yang memiliki self efficacy yang tergolong rendah dan sebagian besar sisanya masuk dalam kategori sedang dan tinggi. Schunk dalam ( Dwyer Kangas dan Fuss, 2002) individu memiliki self efficacy dalam kategori tinggi lebih mudah dalam berpartisipasi dengan orang lain, bekerja keras, dan mampu bertahan dlam menghadapi kesulitan dan tantangan yang dihadapi. Bandura (dalam Rahmawati, 2016) ,menambahkan bahwa individu akan memiliki sikap yang optimis, memiliki pemikiran yang positif, tidak takut pada kegagalan dan dapat mengatasi kecemasan yang dialaminya. Hal serupa juga diungkapkan oleh Patton ( dalam Harahap, Permana \& Astuti, 2016 ) self efficacy tinggi akan memiliki optimism dan harapan serta tidak mudah menyerah saat menghadapi berbagai situasi miaslnya kecemasan bahkan stress.

\section{IV.KESIMPULAN DAN SARAN}

\section{A. Kesimpulan}

Berdasarkan hasil penelitian yang telah dilakukan, maka dapat disimpulkan bahwa hasil uji menyatakan bahwa ada Tidak ada hubungan self efficacy dan tidak signifikan terhadap kecemasan dengan nilai signifikan 0,884 ( $p>0,05$ ) maka Ho di terima dan Ha di tolak jadi semakin rendahnya kecemasan maka semamkin rendah pula self efficacy yang di miliki siswa.

\section{B. Saran}

Berdasarkan kesimpulan yang disampaikan, perlukiranya beberapa saran yang ditujukan kepada penelitian selanjutnya

1. Bagi subjek penelitian

Berdasarkan hasilpenelitian ynag menunjukan bahwa kecemasan yang dimiliki oleh subjek juga tergolong tinggi dan self efficacy yang dimiliki oleh subjek tergolong sedang sehinggga diharapkan siswa untuk dapat menurunkan tingkat kecemasan yang dimiliki.

2. Bagi SMK Negeri 2 Karang Baru

Untuk insitusi penelitian diharapkan dapat membantu siswa dalam menurunkan kecemasan ynag tergolong dalam kategori tinggi.

3. Saran peneliti selanjutnya

Untuk peneliti selanjutkanya diharapkan tidak hanya mengetahui hubungan antara self efficacy dengan kecemasan namun dapat -melihat faktor-faktor self efficacy yang mempengaruhi kecemasan.

Bagi penelitian selanjutnya yang tertarik meneliti tentang hubungan self efficacy terhadap kecemasan diharapkan untuk mencari teori yang lebih baik dan baru terhadap kedua variabel penelitian ini, dan diharapkan juga 
untuk memperhatikan variabel lainnya yang memiliki hubungan yang lebih kuat dengan variabel yang hendak di teliti, serta dapat melakukan uji coba skala dengan jumlah item yang lebih banyak lagi, dengan responden berbeda dan jumlah responden yang lebih banyak sehingga tidak banyak item yang gugur, dan berikanlah pengarahan agar subjek mengisi skala yang disediakan sesuai dengan yang mereka alami.

\section{DAFTAR PUSTAKA}

Anwar, Astrid Indi Dwisty. Hubungan antara self efficacy dengan kecemasan berbicara di depan umum. jurnal psikologi. Universitas Sumatera Utara. Jurnal. 2009.

Delvinasari.Tingkat kecemasan . Universitas Islam negeri Malang. Jurnal.2015

Hartono Dwi Rachmawati. Pengaruh self efficacy terhadap tingkat kecemasan. Fakultas Kedokteran Universitas Sebelas Maret. Jurnal.2012

Listiyani Wulan Laras.Kecemasan berbicara di kelas Universitas Sebelas Maret. Jurnal.2013

Maetiningsih Desiani. Hubungan antara secure attachment dengan motivasi Berprestai pada remaja. Fakuttas Psikologi. Jurnal.2018

Sihombing Nova.Pengaruh self efficacy terhadap kecemasan. Fakultas keguruan dan ilmu pendidikan.Jurnal.2017 